"Influence of income growth on purchasing patterns of luxury cosmetic products among Nigerian customers"

Kajal Bechan
Muhammad Ehsanul Hoque

Kajal Bechan and Muhammad Ehsanul Hoque (2016). Influence of income

ARTICLE INFO growth on purchasing patterns of luxury cosmetic products among Nigerian customers. Public and Municipal Finance, 5(4), 41-47.

doi:10.21511/pmf.05(4).2016.05

DOI

http://dx.doi.org/10.21511/pmf.05(4).2016.05

RELEASED ON

Monday, 26 December 2016

JOURNAL

"Public and Municipal Finance"

FOUNDER

LLC "Consulting Publishing Company "Business Perspectives"

NUMBER OF REFERENCES

0
NUMBER OF FIGURES

0

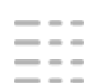

NUMBER OF TABLES

0

(C) The author(s) 2022. This publication is an open access article. 
Kajal Bechan (South Africa), Muhammad Ehsanul Hoque (South Africa)

\title{
Influence of income growth on purchasing patterns of luxury cosmetic products among Nigerian customers
}

\begin{abstract}
Rapid growth of incomes in Nigeria has resulted in increased consumer spending which allowed the emergence of the new market segments, including luxury cosmetic products. Emergence of middle class along with increasing disposable income, increasing urbanization, more females entering the workplace justifies the demand for luxury cosmetics. It is a dream of any women whatever the age group to look and feel beautiful and this is why the cosmetic industry is so large, as cosmetic consumptions by its customers are growing every day. The purpose of the study is to understand the purchasing patterns of the Nigerian consumer who were luxury cosmetic users who frequented the Estee Lauder companies stores in Nigeria. This was a cross-sectional study conducted among 100 consumers who were selected using systematic sampling techniques. A self-administered anonymous questionnaire was used to gather data from respondents. Results indicated that two thirds $(66 \%)$ of the luxury cosmetic users were within the 18-35 age group. Most of the respondents in the study had a full time job and 31\% of the respondents earned between 132,001 - 379,000 naira, which equates to $\$ 660-\$ 1897$. Respondents revealed that their top three luxury cosmetic brands were MAC, Estee Lauder and Bobbie Brown. Consumers are aware of the benefits associated with luxury products, therefore, this market segment must be exploited, as it has untapped potential and opportunity.
\end{abstract}

Keywords: cosmetics, luxury cosmetic market, purchasing patterns, Nigerian consumer.

JEL Classification: D11, D12, L66.

\section{Introduction}

Although much research has been conducted on the luxury cosmetic market globally, there is limited research that exists currently in relation to the Africa market. Information has been gathered on Africa in terms of business and strategy to enter the luxury cosmetic market, but limited information exists in terms of understanding the luxury cosmetic user. The emerging middle class in Africa has also contributed to expand the sales in the luxury cosmetic market. Since Nigeria has a rapidly expanding middle class that is consuming luxury cosmetic products, the study will look at this segment in the African cosmetic market. The branding of luxury cosmetic products is also an important factor to consider, as consumers purchasing decisions revolve around the cosmetic brand that they are loyal to. Luxury products can be made up of makeup or body care products. Luxury cosmetics can be broken down further into the following sub categories, namely, skin/face care; fragrances; make up and body care. Estee Lauder is a luxury cosmetic brand that caters to the needs of women in make-up and body care products. This paper will focus on the luxury cosmetic user that enters the Estee Lauder stores in Nigeria. For the purpose of this study, the researchers focused on skin/face care and make-up as these are the two largest categories in the luxury

(C) Kajal Bechan, Muhammad Ehsanul Hoque, 2016.

Kajal Bechan, MBA graduates, Graduate School of Business and Leadership, University of KwaZulu-Natal, South Africa.

Muhammad Ehsanul Hoque, Dr., Academic Leader: Higher Degrees and Research, Graduate School of Business and Leadership, University of KwaZulu-Natal, South Africa. cosmetic segment in Nigeria. The objective of this study was to identify Nigerian customers purchasing patterns of luxury cosmetic products.

\section{Literature review}

The literature review will outline themes in the discussion on the opportunity to market luxury cosmetics in Africa, consumer buying patterns of cosmetics and the Nigerian consumer of luxury cosmetics.

1.1. The opportunity to market luxury cosmetics. Łopaciuk and Łoboda (2013) posit that globally the market for luxury cosmetics has been drastically impacted by the recent economic downturn. However, analysts predict that the economic recovery that follows would increase the demand for luxury products, as more disposable income becomes available to the global customers. The global beauty market is usually divided into five main business segments: skincare, hair care, colour (make-up), fragrances and toiletries. These segments are complementary and, through their diversity, they are able to satisfy all consumers' needs and expectations with regard to cosmetics. Beauty products can be also subdivided into premium and mass production segments, according to the brand prestige, price and distribution channels used. Lopaciuk and Loboda (2013) suggest that $72 \%$ of cosmetic sales were made up of mass products and the remaining $28 \%$ contributed to prestige cosmetics.

Leonard, McDade, Tanner, Vadez \& Seyfried (2011) state that since 2000, the BRIC countries (Brazil, Russia, India and China) have been showing signs of exponential growth. The growth of the beauty market contributed significantly to the global market as these four countries contributed 
$21 \%$ to the global beauty industry. Łopaciuk and Łoboda (2013) argue that there has been an increased desire for international cosmetic manufactures to expand their footprint into the emerging markets. They want to expand their business, since they believe that there is a demand for their product in the emerging market. A major challenge to these international cosmetic companies is making their brands locally relevant to the local customer. Collins and Weiss (2015) discussed the opportunity of empowering rural consumers in emerging markets. They reflect on the understanding required by manufacturers on African skin specificities and to deliver tailored products to this consumer base. Mckinsey (Africa Consumer Insights Center, 2012) argues that research indicates that the African consumer is brand loyal and, once settled on a particular brand, will stay loyal with hesitance to change or try new things. He adds further that as the African consumer is exposed to more choices, quality and brand play a significant role in the purchasing decision behavior.

Truong (2010) adds that in recent years, the demand for luxury goods has increased steadily. The economic factors driving this trend include urbanization, the emerging middle class, an increasing rate of females in the work force, a substantially lower employment rate and an increase in disposable income which has led to a booming wealthy class in emerging markets.

1.2. Consumer buying patterns for cosmetics. Acquiring knowledge on consumer behavior can add to the success of the organization. Market leaders are constantly gathering insights and analyzing the patterns of buyer behavior and purchasing decisions to estimate future trends (Kumar, John \& Senith, 2014). The first thing which influences the consumer behavior and shapes is culture. Culture builds the strong perceptions of the products in the mind of the customers (Guthrie, Kim \& Jung, 2008). According to Rai (2013), there are several national and international brands which people recognized and have strong perception in their minds. These perceptions are pinched in their mind because of their culture, life styles and surroundings. Jawahar and Tamizhjyothi (2013) argue that attitudes are formed through experience and learning and it are those attitudes that can influence the buying behavior in a consumer.

Voss, Parasuramanand Grewal (1998) in their studies have examined the difference rational behind the selection of cosmetic products. They identified price as a driving factor over quality during prepurchase evaluation; however, after purchases, quality mattered more than price. Vigneron and Johnson (1999) reported in their study that there was a steep increase in the need for people to look good. Self- image and appearance were important considerations in today's society. This has been reflected in research across the world, as the boom in the cosmetic segment has risen. According to Africa Focus (2006), the buying decision process does not differ in terms of the stages, but the level of involvement is a considerable difference. The assumption is that prestige products are not bought frequently and require a high level of knowledge and interest.

Nigerians are among the most prosperous people in the West African region, and the culture and habits of Nigerian women are changing. Nigerian women are investing more on their appearance and beauty and, for this reason, they use more cosmetic products. Nigerian women are found to spend more than the EU12 and even more than French women according to World Economic Database. The factors that affect more customers' decision for buying cosmetic products are, first, quality and, then, brand name and price. Mohiuddin, Parveen, Rahman and Su (2014) argue that to make color cosmetics more acceptable to consumer; manufacturers would have to convince them that their products are of good value. The women prefer to shop for cosmetic products from beauty shops. They, then, frequent shops in malls to look for their cosmetics. A last option is to buy their cosmetic stores from informal street traders. Estee Lauder's customers prefer to shop for their products from malls and, then, if they fail to acquire their beauty range, then, they shop at the beauty stores.

Despite, the majority of the population was living in poverty in Nigeria and facing economic challenges, the youth bulge and rapid rate of urbanization presented promising growth opportunities. In addition, middle- and high-income consumers are enjoying rising levels of disposable income, increasing their demand for a wider range of products and services (Dauriz, Remy \& Sandri, 2014). Mckinsey's (Africa Consumer Insights Center, 2012) stated in a study that $70 \%$ of Nigerians are brand loyal, $60 \%$ of Nigerians want high quality, $69 \%$ of Nigerian's want high fashion, but international brands are not perceived to be more fashionable than local brands and $47 \%$ of Nigerians wanted a convenient, modern, shopping experience with an excellent in-store environment.

The positioning of the brand is dependent on the success and failure of the company. Marketers in the cosmetic industry are continuously finding ways to bring new and innovative products for their customers. Along with this, they are also focusing on making the most attractive and appealing advertisements, so that they can attract more and more customers. They can attract the customers by providing the best services and assuring high quality cosmetic products (Xu Yang, 2012). Cosmetic companies are making the standardized products for the consumers all over the world. 
This gives them way to create the strong brand image and personality in the mind of the customers. Companies want to spread the same brand image all over the world, so, they are showing the standardized commercials all over the world (Ivančová, 2013)

\section{Methodology}

This was a cross-sectional descriptive study conducted among consumers buying luxury cosmetics in Nigeria to determine the buying patterns of the African consumer. The location of the study selected was Nigeria due to it being the largest business for cosmetics and luxury goods. To determine the participants in the study, the target market would need to be defined. The target population would be determined by elements such as geography, age, demographics (Sekaran, 2010). Based on camera CCTV footage, about 514 customers enter the store in a month (on a weak performing month). From the 514 customers, $60 \%$ enter over a month end pay weekend. That leaves the remaining 208 customers shopping over the rest of the month. For the purpose of this study, a sample of 100 was used to gather data. The sample size is an assumption based on the quieter morning/afternoon periods over the first two weeks of the month. A non-probability sampling technique was used, as it allows for the research to lean towards descriptive research.

A hard copy of the questionnaire was distributed to consumers entering the stores of Estee Lauder companies during off peak hours to those customers that are browsing the store. The rationale behind not using peak periods is to avoid causing any disturbance in store (customers feeling obligated to complete the questionnaire, staff feeling overwhelmed leading to poor customer service, and incomplete questionnaires due to busy store environment). The questionnaire was developed based on the literature review and experience of the researcher in the field. The questionnaire was pretested among 10 consumers to test the understanding and flow of the questions and adjustments were made to wording of questions.

The study was ethically approved by the ethics committee of the University of KwaZulu-Natal prior to conduct the study. Also, permission was obtained from the shop manager to approach the customers. Participation in the study was voluntary. Participants could withdraw from the study anytime, if they wished do without any penalty. Anonymity and confidentiality was maintained at all times.

\section{Findings and discussion}

A total of 100 consumers completed the questionnaire. It was found that two-thirds of the consumers were 35 years old or younger (Figure 1). These are the millennial consumers that make very informed and educated decisions. Knowing the age group of the luxury cosmetic consumer assists the researcher to build a strong marketing plan to target these specific groups. Studies indicate that factors like demographics with regards to age, income, etc., are factors that gain a competitive advantage over competitors in a market. Gender also plays a significant role in consumer behavior (Pentz, Terblanche and Boshoff, 2014)

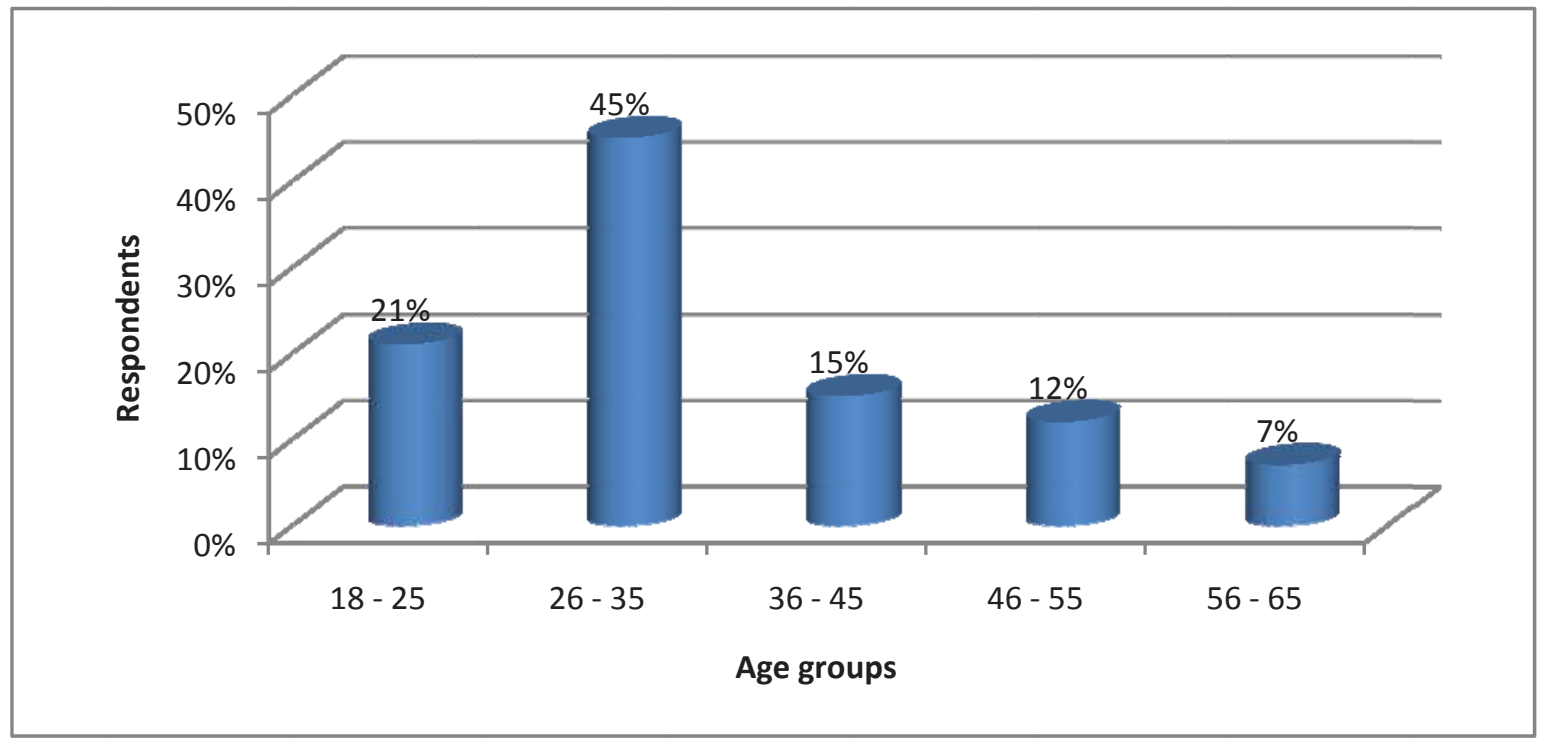

Fig. 1. Consumer age groups distribution

Further to the analysis, most respondents have a full time job and $31 \%$ of the respondents earn between 132,001 - 379,000 naira, which equates to $\$ 660$ $\$ 1897$. These are the emerging middle class that are entering the workplace, increasing disposable in- come, increasing urbanization, more females entering the workplace, hence, in line with the justification of the demand for luxury cosmetics.

Income levels are important to consider in the luxury segment. As people earn more, they tend to 
travel more and are exposed to more variety of products and services on an international scale. Their expectations and attitudes change as compared to those that do not travel or have not been exposed to any different to current norms in their market (Pentz, Terblanche and Boshoff, 2014) what marketers can also see from income levels are the level of education which links to purchasing habits, the educated office worker will focus more on her image and touch up her make up before meetings. Income levels also indicate the amount of spend available on luxury goods (Khraim, 2010). Low income groups will tend to focus on basics first before moving onto any additional. Whilst identifying, the emerging middle class and higher income groups show a marketer whom to focus on and what communication elements to utilize, to target these segments.

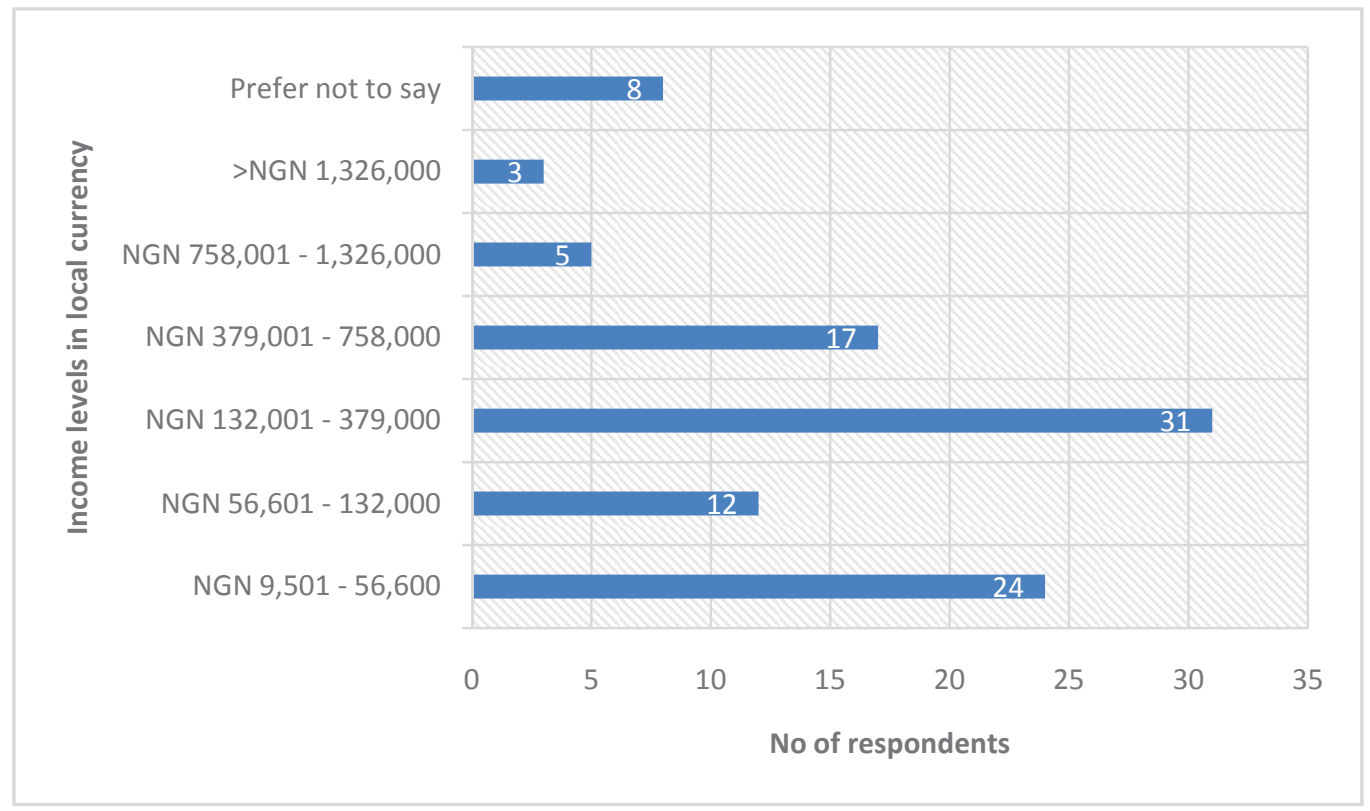

Fig. 2. Monthly income per consumer

The illustration (Figure 1, see Appendix) shows the respondents preference to luxury cosmetic brands. The bar chart representation clearly indicates that MAC, Estee Lauder and Bobbie Brown rank top three for the consumer in Nigeria. The present study found that almost all the participants (90\%) reported of using skin/face care products at morning and night. Make-up is distributed across the day with $36 \%$ indicating they use at morning, 27\% indicated during the day and $18 \%$ using their products at morning and night (Figure 3).
The importance of knowing product usage is an opportunity to understanding the customer needs to build useful products. In the data gathered and analyzed for this study, the demand for products that focus on pigmentation and repair serums relate back to the climate and the need for skin protection. Whitening and lightening products are on the increase in Africa, as the lighter skinned female's feel of higher status. Harm chemicals and skin peels are being used resulting in long-term skin damage.

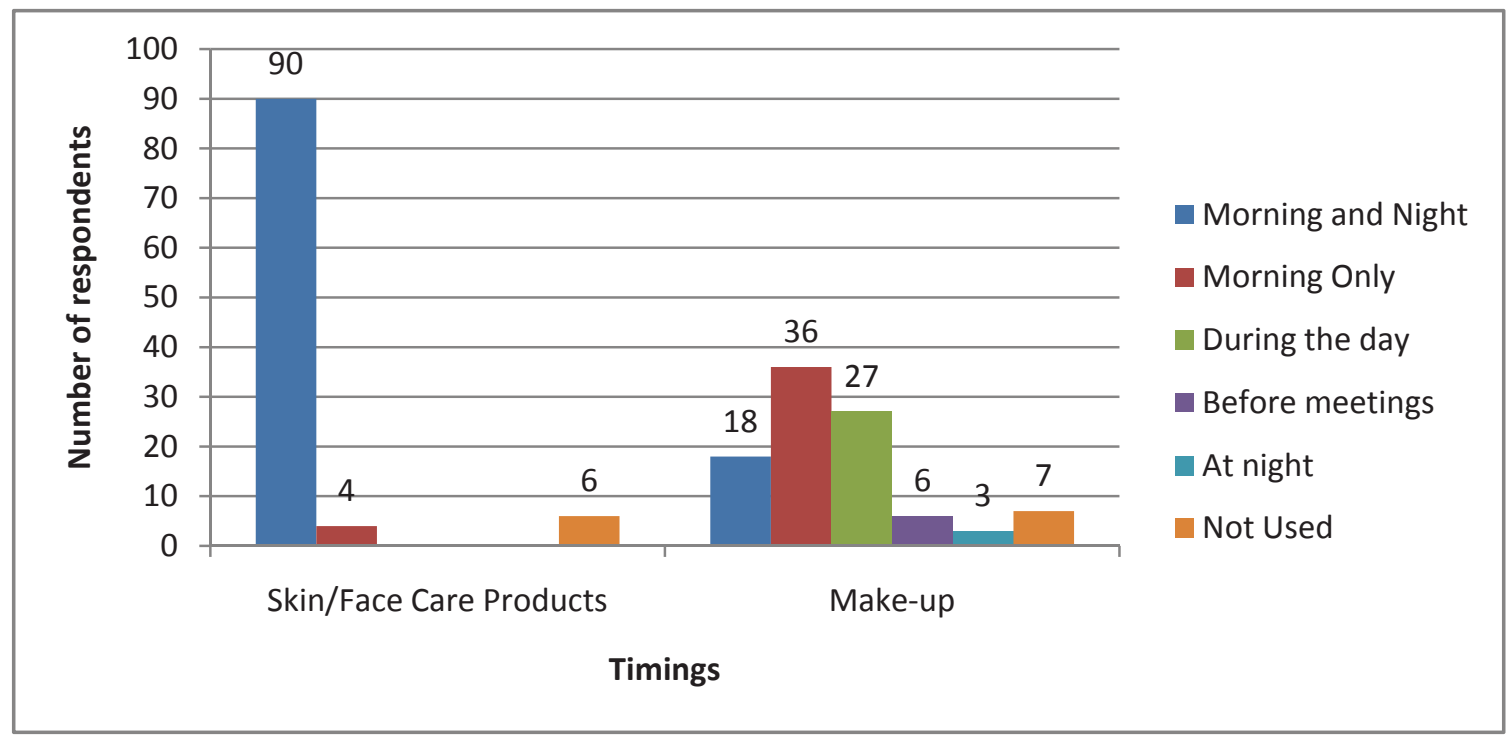

Fig. 3. Frequency of using cosmetics 
From the data analyzed in this study, about half $(46 \%)$ of respondents ranked promotions as important whilst $37 \%$ indicated that they were neutral. Integrated marketing communications (IMC) are defined as the process of managing all sources of information about a product/service to which a customer or prospect is exposed, which behavirally moves the consumer toward a sale and maintains customer loyalty (Reinold and Tropp, 2012). This is a marketing strategy that recognizes that the combined effect of various communications tools used in conjunction with each other will result in higher brand awareness and, subsequently, positive brand image. Top of mind for the majority of females and evidently males today is the pursuit of eternal youth. They have adopted healthier lifestyles and made more conscious purchasing decisions mainly driven by advanced social media platforms. These educated decisions have led to the use of more flamboyant marketing terms and claims on packaging (Meng and Pan, 2012).

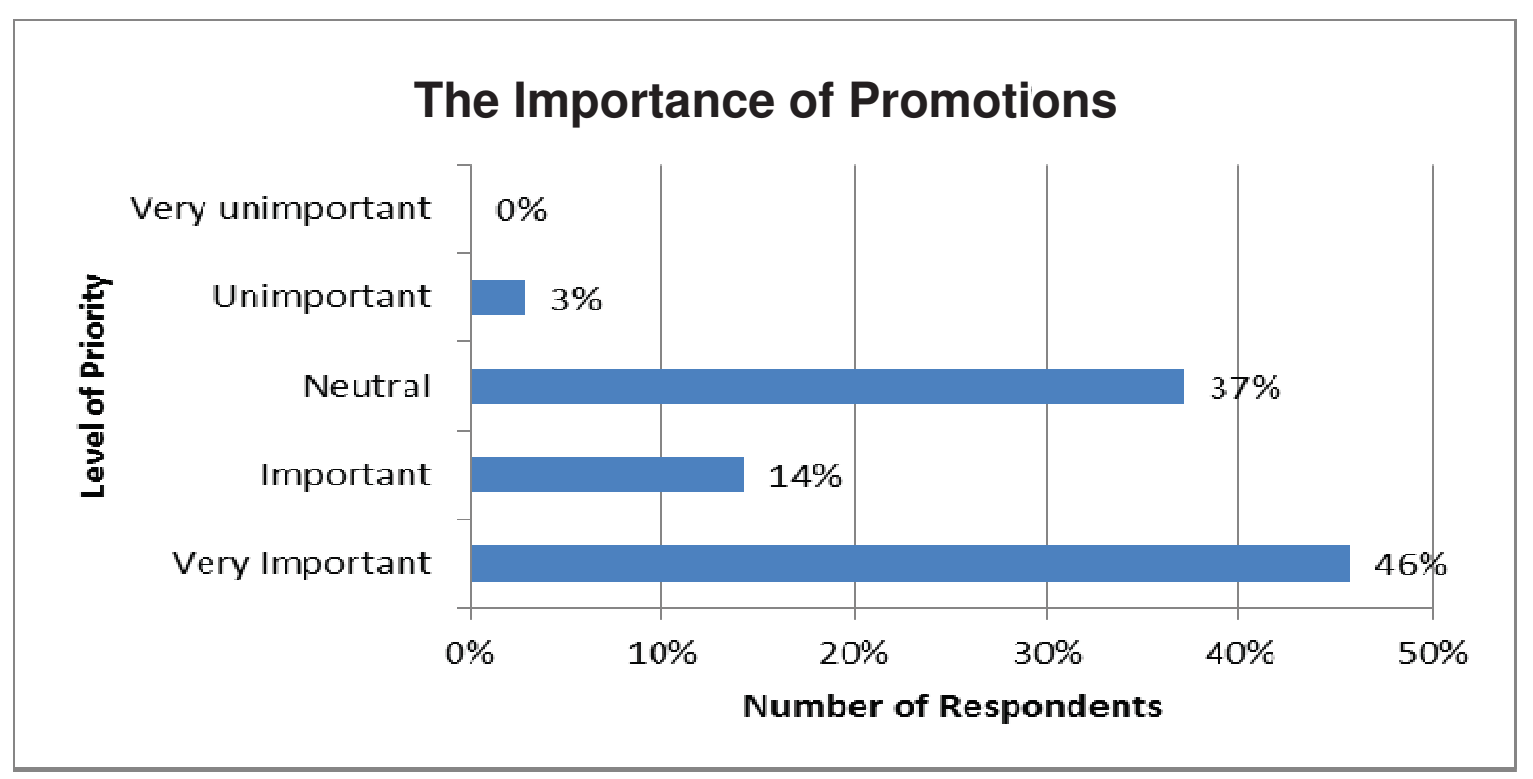

Fig. 4. The importance of promotions

In Figure 5, it was found that majority (70\%) of the respondents spent between $\$ 151-\$ 350$ on their luxury cosmetic products.

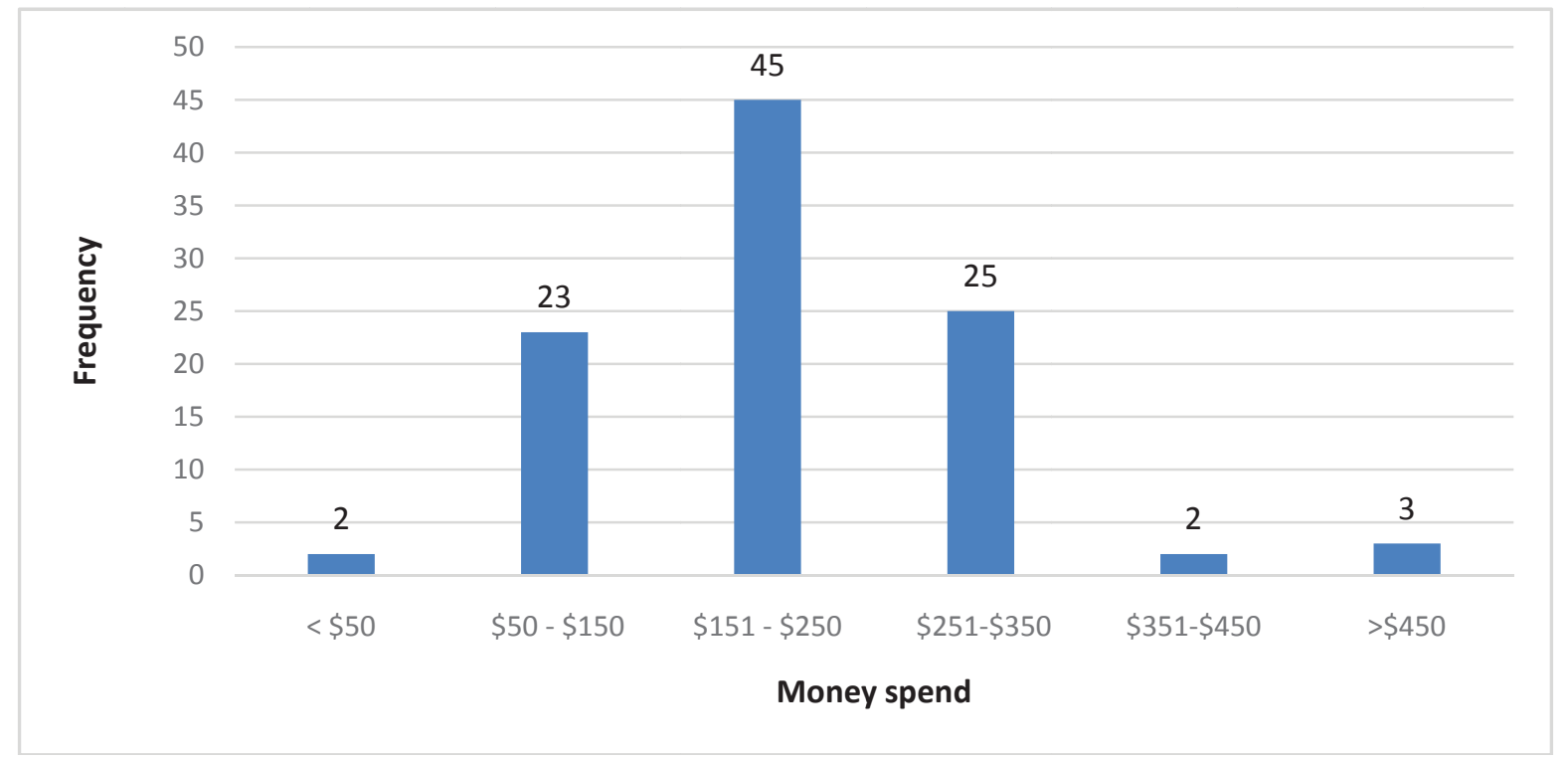

Fig. 5. Amount of money spend on cosmetic products among consumer in Nigeria

\section{Recommendations to management}

The management team should tailor locally relevant and quality products for the Nigerian market that is critical for brands going into the region of Africa.
The youth of Africa are different by each market, hence, each market requires a local strategy by market, as the needs differ. The humidity of the African climate, for example, is a critical factor to be considered for skin care products, as well as make-up. In 
the European markets, waterproof make-up is huge for consumers that enjoy water sports, whereas the need in Africa is for waterproof and long lasting make-up based on the climate. The need for darker shades of make-up for the African consumer leads to revised product line ups which result in by door strategies in Africa. High expatriate locations would need a full product assortment versus the rural locations that would not need lighter shades of make-up, but the demand for the darker shades would be higher. Also, the local municipalities should try and build more shopping malls for price to be more competitive.

\section{Tailor luxury cosmetics to the consumer segment.}

The reinvestment of information to make better and improved product decisions can be built into the strategy of this organization. Since product innovation is what sets brands apart consumers today are looking for convenience, they are focusing on the healthy organic trends in products, and more youthful looking skin is a reflection on the person itself. Consumers know what they want and are willing to pay the price for quality and value for money, but, at the same time, in luxury, purchasing comes good customer service which needs to be tailored to the market and consumer specifically.

\section{Proper promotion of the luxury cosmetics should be in place.}

Word of mouth is still a medium that is gospel to the African consumer. Referrals and sharing of informa- tion via friends and women groups are considered reliable and trustworthy. These factors are imperative when considering the search for information step in the buying decision process.

\section{Staff should be trained so that they know how to handle clients and customers.}

Considering the above implications, organizations need to factor these elements of recruitment and training into their project timelines and go to market strategies. Over and above, recruitment and training retention needs to also be considered as entrants of competing brands enter the market those already recruited and trained become viable candidates for these competing companies. Organizations need to build talent pools in each market and ensure developmental plans are in place. As expansion into Africa takes place, the existing teams need to be promoted to ensure succession planning takes place. Having to recruit, train and retain millennia's organizations need to understand this current workforce and their desire to grow in company's at a rapid pace.

\section{Conclusion}

Having conducted an in-depth study on the luxury cosmetics market in Nigeria, the results indicated the importance of understanding this market, as the consumers in this market have the money and power to make purchasing decisions. Consumers are aware of the benefits associated with luxury products, therefore, this market segment must be exploited as it has untapped potential and opportunity.

\section{References}

1. Africa Focus. (2006). Sights and Sounds of a Continent, Choice Reviews Online, 44 (4), pp. 44-63.

2. Collins, M. and Weiss, M. (2015). The role of provenance in luxury textile brands, International Journal of Retail \& Distribution Management, 43 (10/11), pp.1030-1050.

3. Dauriz, L., Remy, N. and Sandri, N. (2014). Luxury shopping in the digital age. McKinsey Insights: McKinsey \& Company.

4. Guthrie, M., Kim, H.S. and Jung, J. (2008). The effects of facial image and cosmetic usage on perceptions of brand personality, Journal of Fashion Marketing and Management: An International Journal, 12 (2), pp. 164-181.

5. Ivančová, A. (2013). Is it about money or marketing? International marketing strategies in the luxury cosmetic industry exploratory multiple case study of Chanel, Guerlain and La Mer. GRA 19003 - Master thesis.

6. Jawahar, J.V. and Tamizhjyothi, K. (2013). Consumer attitude towards cosmetic products, International Journal of Exclusive Management Research, 3 (6), pp. 608-625.

7. Keller, K.L. (2013). Strategic Brand Management. England, Pearson Education Limited.

8. Khraim, H.S. (2010). Cosmetics Buying Behavior of Young UAE Female Consumers: The Influence of Demographics, Skyline Business Journal, 5 (1), pp. 2010-11.

9. Kumar, A.H., John, S.F. and Senith, S. (2014). A Study on factors influencing consumer buying behavior in cosmetic Products, International Journal of Scientific and Research Publications, 4 (9), pp. 1-6.

10. Leonard, W.R., McDade, T., Tanner, S., Vadez, V. and Seyfried, C. (2007). Signaling by consumption in a native Amazonian society, Evolution and Human Behavior, 28 (2), pp. 124-134.

11. Lopaciuk, A. and Loboda, M. (2013). Global beauty industry trends in the 21st century, In Management, Knowledge and Learning International Conference, 19-21 June, Zadar, Croatia.

12. Mckinsey's Africa Consumer Insights Center. (2012). The rise of the African Consumer. [Online]. Johannesburg, pp. 1-24. Available at: http://www.mckinsey.com/global_locations/africa/south_africa/en/rise_of_the_african_consumer [accessed 12 September 2015].

13. Meng, J. and Pan, P.L. (2012). Investigating the effects of cosmeceutical product advertising in beauty care decision making, International Journal of Pharmaceutical and Healthcare Marketing, 6 (3), pp. 250-266. 
14. Mohiuddin, M., Parveen, R., Rahman, M.I., and Su, Z. (2014). Motivational factors influencing social entrepreneurship in Bangladesh, In ElieChrysostome \& Rick Molz (Eds.) Building Businesses in Emerging and Developing Countries: Challenges and Opportunities. London/NYC: Routledge.

15. Pentz, C., Terblanche, N. and Boshoff, C. (2013). Measuring Consumer Ethnocentrism in a Developing Context: An Assessment of the Reliability, Validity and Dimensionality of the CETSCALE, Journal of Transnational Management, 18 (3), pp. 204-218.

16. Rai, N. (2013). Impact of advertising on consumer behavior and attitude with reference to consumer durables, International journal of management research and business strategy, 2 (2), pp. 75-87.

17. Reinold, T. and Tropp, J. (2012). Integrated marketing communications: How can we measure its effectiveness? Journal of Marketing Communications, 18 (2), pp. 113-132.

18. Sekaran, U. and Bougie, R. (2010). Research methods for business: a skill-building approach. 5th ed. Chichester, NJ: Wiley.

19. Truong, Y. (2010). Personal aspirations and the consumption of luxury goods, International Journal of Market Research, 52 (5), pp. 655-673.

20. Vigneron, F. and Johnson, L.W. (2004). Measuring perceptions of brand luxury, Journal of Brand Management, 11 (6), pp. 484-506.

21. Voss, G.B., Parasuraman, A. and Grewal, D. (1998). The roles of price, performance, and expectations in determining satisfaction in service exchanges, The Journal of Marketing, 62 (2), pp. 46-61.

22. Xu Yang, S.J. (2012). Ideal Types of Strategic Innovation: An Exploratory Study of Chinese Cosmetic Industry, International Journal of Business and Management, 7 (17), pp. 78-87.

\section{Appendix}

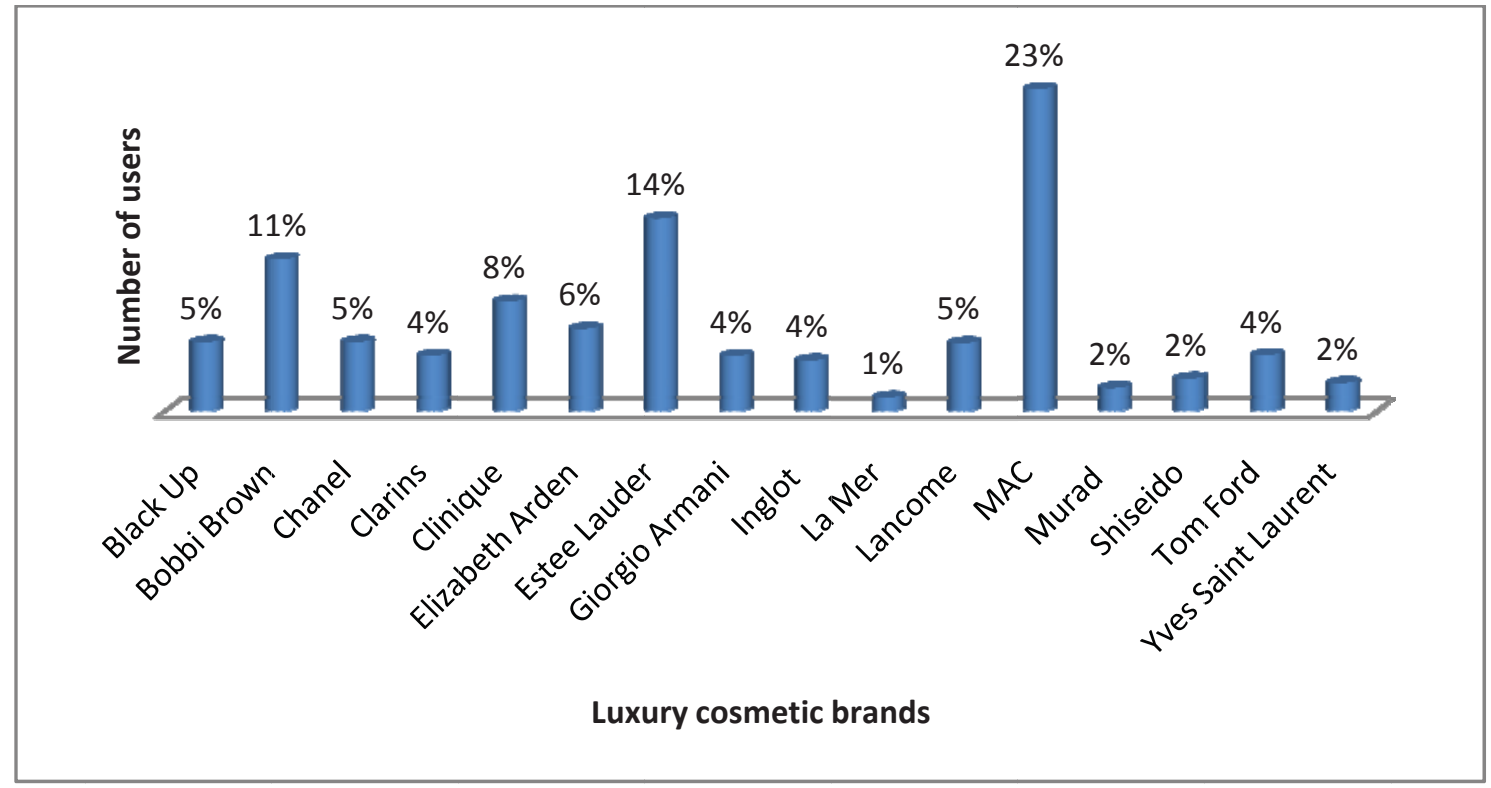

Fig. 1. Popular cosmetic brands in Nigeria 